\title{
A methodology to measure sight-hidden dips' parameters
}

\author{
Maria Castro $^{\mathrm{a}, *}$, Luis Iglesias ${ }^{\mathrm{b}}$, Roberto Rodríguez-Solano ${ }^{\mathrm{c}}$, José A. Sánchez ${ }^{\mathrm{d}}$ \\ a Dept. Transportes, E.T.S.I.C.C.P., Universidad Politécnica de Madrid, Prof. Aranguren s/n, 28040 Madrid, Spain \\ ${ }^{\mathrm{b}}$ Dept. Explotación de Recursos Minerales y Obras Subterráneas, E.T.S.I.M., Universidad Politécnica de Madrid, Ríos Rosas, 21, 28003 Madrid, Spain \\ ${ }^{\mathrm{c}}$ Dept. Construcción y Vías Rurales, E.U.I.T.F., Universidad Politécnica de Madrid, Avda. Ramiro de Maeztu s/n, 28040 Madrid, Spain \\ ${ }^{\mathrm{d}}$ Dept. Ingeniería Civil: Hidráulica y Energética, E.T.S.I.C.C.P., Universidad Politécnica de Madrid, Prof. Aranguren s/n, 28040 Madrid, Spain
}

Keywords:

Sight distance

Diving

Sight-hidden dips

Traffic safety

Global Navigation Satellite System (GNSS)

\section{A B S T R A C T}

Highway design standards specify several requirements on available sight distance. Usually, compliance with these standards is ensured during the design phase of a new road. This is made through geometric calculations that take into account the terrain and the road. In this paper, a procedure for measuring distances in an existing road from georeferenced photographs is proposed. In addition, an estimation of the error committed when using this procedure is made. Distances measured using this procedure are compared with the ones measured using a Global Navigation Satellite System (GNSS). Distances error is within the error estimation and is low enough for using it in traffic safety studies. In addition, the procedure is applied to measure several parameters of a sight-hidden dip. This procedure does not need a terrain model to measure these parameters. This is an advantage compared with other existing procedures for estimating the parameters of sight-hidden dips.

\section{Introduction}

Highway design standards specify several requirements on available sight distance (Fig. 1). Usually, compliance with these standards is ensured during the design phase of the road. This is made through geometric calculations that take into account the terrain and the road.

On the other hand, some combinations of horizontal and vertical alignments can produce shortcomings in 3-D perspective. Among the safety-related shortcomings, the partial disappearance of a road from the driver's view with reappearance in the extension of the just-passed roadway section (called dip or diving) (Fig. 2) stand out. When connecting a crest vertical curve, followed by a sag, the road may disappear from driver's view to reappear later. Then,

* Corresponding author. Tel.: +34 91 3366653; fax: +34 913366654.

E-mail addresses: maria.castro@upm.es (M. Castro), luis.iglesias@upm. es (L. Iglesias), roberto.rodriguezsolano@upm.es (R. Rodríguez-Solano), joseangel.sanchez@upm.es (J.A. Sánchez). there is a loss of path or a diving in the road. It is essential to avoid losses when they hide dangerous points, such as intersections or unexpected changes in direction. This loss can produce driver disorientation if visible sections are nearby and visual indicators suggest that hidden section alignment is similar to visible sections alignment. This disorientation could cause erroneous decisions, which could cause an accident. In addition, in the case of an overtaking, a driver could believe that he could see all possible vehicles circulating towards him. However, this is could not be the case because some unnoticed vehicles could be in the hidden section.

When a car arrives at station $\mathrm{A}$, the driver sees the phenomenon. The car follows the path and after some time (seconds), it could see the usual (correct) road perspective. Between the first and second mentioned stations, there are highway sections hidden to a driver and highway sections that "reappear". Length of diving is the difference between the first station, in which divers could see the phenomenon, and the second station (first station in which the phe- 


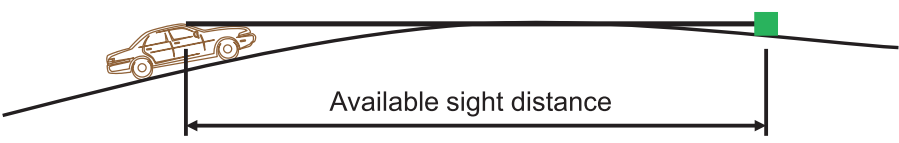

Fig. 1. Available sight distance.

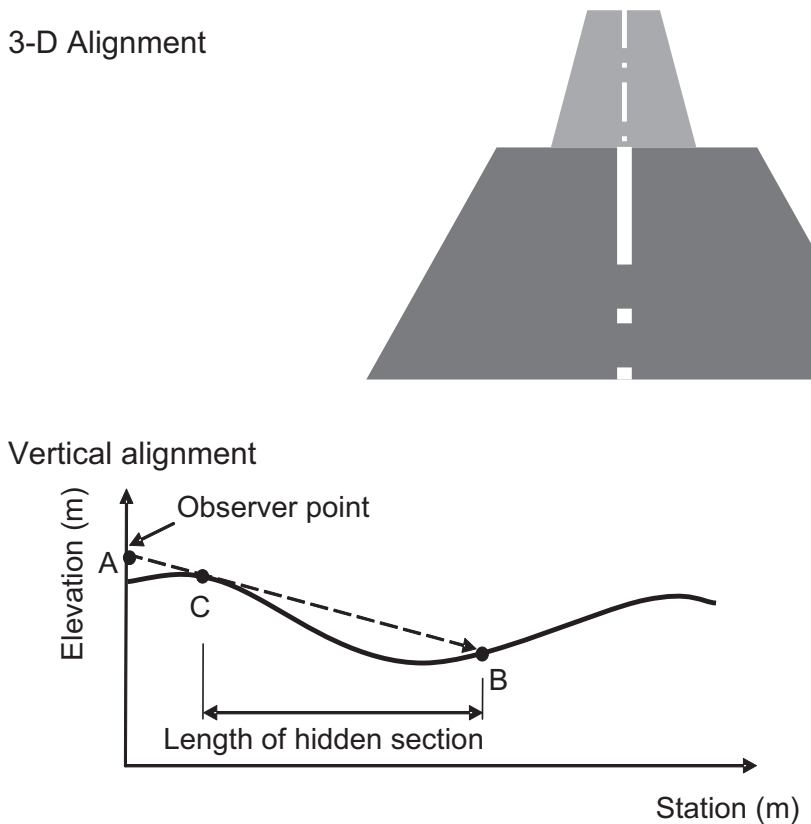

Fig. 2. Hidden-sight dip or diving.

nomenon does not exist). Length of diving is important to characterize a diving because, if it is very small, drivers could be not aware of the existence of a diving. Other relevant parameters are maximum length of hidden section ( $C B$ in Fig. 2) and maximum distance between driver and reappeared section $(A B)$. The Swiss standard [1] and Italian standard [2] state that the reappeared section should be at a large enough distance from the observer. Both standards provide similar distance values. Nevertheless, while Swiss standard provides these minimum distances through a graphic, Italian standard provides them through a table. As could be seen (Table 1 ), these distances vary between $150 \mathrm{~m}$ for a vehicle's operating speed of $25 \mathrm{~km} / \mathrm{h}$ and $860 \mathrm{~m}$ for $140 \mathrm{~km} / \mathrm{h}$. AB distance from observer to reappeared section (Fig. 2) should be larger than this critical distance.

Most researches show the importance of 3D shortcomings, specifically divings, but they consider the problem usually from a qualitative point of view [3,4]. To aid designers, highway design standards include recommendations (rules applicable in the design phase of a highway) about horizontal and vertical layout coordination in order to avoid 3D alignment shortcomings [5,6]. Most of these recommendations are qualitative. However, shortcomings can still occur in the three-dimensional alignment. Even for experienced design engineers, despite these recommendations (rules), and they are not recognized until the road has been built.
Table 1

Critical distance from driver to reappeared section according to Italian standard [2].

\begin{tabular}{cl}
\hline Speed $(\mathrm{km} / \mathrm{h})$ & $\begin{array}{l}\text { Distance from observer to } \\
\text { reappeared section }(\mathrm{m})\end{array}$ \\
\hline 25 & 150 \\
40 & 180 \\
50 & 220 \\
60 & 280 \\
70 & 350 \\
80 & 420 \\
90 & 500 \\
100 & 560 \\
110 & 640 \\
120 & 720 \\
130 & 800 \\
140 & 860 \\
\hline
\end{tabular}

On the other hand, more recently, highway design software that could generate virtual images of the designed highway is available. In order to check these images, designers should see them sequentially. These procedures are aimed to be applied in the design phase of a highway, and they require knowledge about project data (horizontal and vertical layout and cross section) [7-9]. In this way, if shortcomings are detected, the design could be modified. These procedures do not take into account quantitative aspects of the phenomenon and applying them to already 
built highways is difficult because project data could be unknown (length of tangents, curves radii, spirals, geometric characteristics of vertical curves, etc.).

Easa [10] developed equations for quantitative analysis of divings [10]. These equations are applicable if involved sections are in a horizontal tangent. More recently, Zimmermann [11] and Zimmermann and Ross [12] and Kunh and Jha [13] have proposed a methodology for checking shortcomings in the three-dimensional alignment in order to help design engineers [11-13]. Their method has the novelty of including hidden depth as an important diving parameter. This method could be applied during highway design. They have used several software applications (mathematical software and highway design software). These quantitative procedures [10-13] need some project data (curves radii, spirals, vertical grades, geometric characteristics of vertical curves etc.) or a 3D alignment definition. Therefore, applying these procedures to already built highways could be difficult (because usually needed data are unknown).

In case of already built highways, shortcomings could be detected through visualization of video inventories. However, it is a slow and usually costly process. On the other hand, Castro et al. [14] have proposed a procedure to find divings based on determining, for each highway station, what sections ahead are visible and what are hidden. This procedure is especially useful for existing roads and uses a software that has been developed for the calculation and analysis of sight distances, based on ArcGIS. It requires a digital terrain model (DTM) of the studied road and the path followed by vehicles. Procedure accuracy depends on DTM resolution and distance between calculation points [14].

As mentioned, diving relevance is related with the values of the parameters involved in the problem as length of hidden section (CB in Fig. 2), length of diving, distance between driver and highway reappearance (AB in Fig. 2) and available sight distance (AC in Fig. 2). For this reason, a measurement of the aforementioned parameters could provide a deeper understanding of divings.

The objective of this research is to develop a method for measuring some parameters involved in divings of existing roads without requiring the use of any specific software (e.g. GIS) or any project information. This method for measuring parameters of previously identified divings uses images taken in road. It is presented in the first part of this paper and is followed by a discussion of the possible sources of error and their impact. Finally, an application of the method to a case study is presented. This case study includes a verification of the procedure.

\section{Procedure for measurement of distances in roads through photography}

The aim of the procedure is determining the length of sections $A B, A C$ and $C B$ (Fig. 2) from photographs taken in road. These photographs can be taken using conventional cameras. The procedure does not need using any specific software and it is based in geometrical relations between variables. In what follows, it is assumed that the whole road section analysed is in a horizontal tangent.
$\mathrm{AA}^{\prime}$ is carriageway width (measured on a photo) in the station where hidden section starts. $\mathrm{BB}^{\prime}$ is carriageway width (measured on a photo) in the station where hidden section ends (i.e.: in the beginning of the reappeared section) (Fig. 3).

In order to simplify calculations, it is assumed that points $A$ and $A^{\prime}$ (Fig. 3 ) are on a straight line. For the same reason, it is also assumed that points $B$ and $B^{\prime}$ (Fig. 3) are on another straight line. In reality, $\mathrm{AA}^{\prime}$ and $\mathrm{BB}^{\prime}$ are not perfect straight lines due to cross section slope. This slope is needed to easy water flowing out of the carriageway. In a road, the line $A A^{\prime}$ (start of hidden section) is nearer to the observer than the line $\mathrm{BB}^{\prime}$ (end of hidden section, i.e.: start of reappeared section), although in a photograph they superpose (Fig. 3).

Therefore, it could be assumed that observation point and lines $\mathrm{AA}^{\prime}$ and $\mathrm{BB}^{\prime}$ are on the same plane in space. Thus, the aim is determining distance between those lines from the distances $\mathrm{AA}^{\prime}$ and $\mathrm{BB}^{\prime}$ measured on a photo.

\subsection{Geometrical analysis in camera space}

Fig. 4 shows the variables involved in the geometrical analysis of a photograph of a diving: centre of projection, focal length, width of focal plane, lines $\mathrm{AA}^{\prime}$ and $\mathrm{BB}^{\prime}$, and angles $\alpha_{1}, \alpha_{2}$ y $\alpha_{3}$.

At least two data from the camera are needed: focal length (distance at which a beam of collimated light will be focused to a single spot) and pixel resolution (mm/pixel) or width of focal plane. From the coordinates of points $A, A^{\prime}, B, B^{\prime}, G$ and $F$, measured in pixels on the photo, length of segments $\mathrm{FG}, \mathrm{AA}^{\prime}$ and $\mathrm{BB}^{\prime}$ could be determined. From these lengths, angles $\alpha_{1}, \alpha_{2} \mathrm{y} \alpha_{3}$, which are observation angles of width of focal plane, segments $\mathrm{AA}^{\prime}$ and $\mathrm{BB}^{\prime}$ on the photo, respectively, could be determined. FG distance is the width of focal plane of the sensor.

The coordinates of a point in pixels are the row and column corresponding to the pixel where the point is located. Knowing pixel resolution, the coordinates of a point in millimetres are obtained multiplying pixel row and column

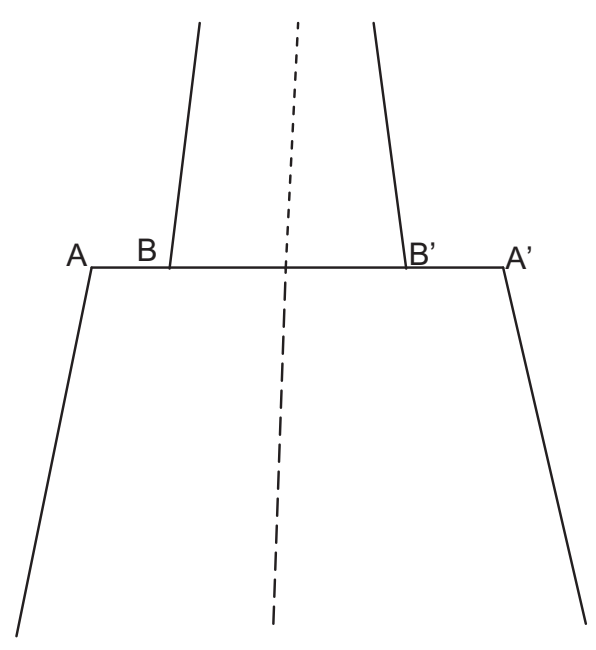

Fig. 3. Carriageway widths on a photograph of a diving. 

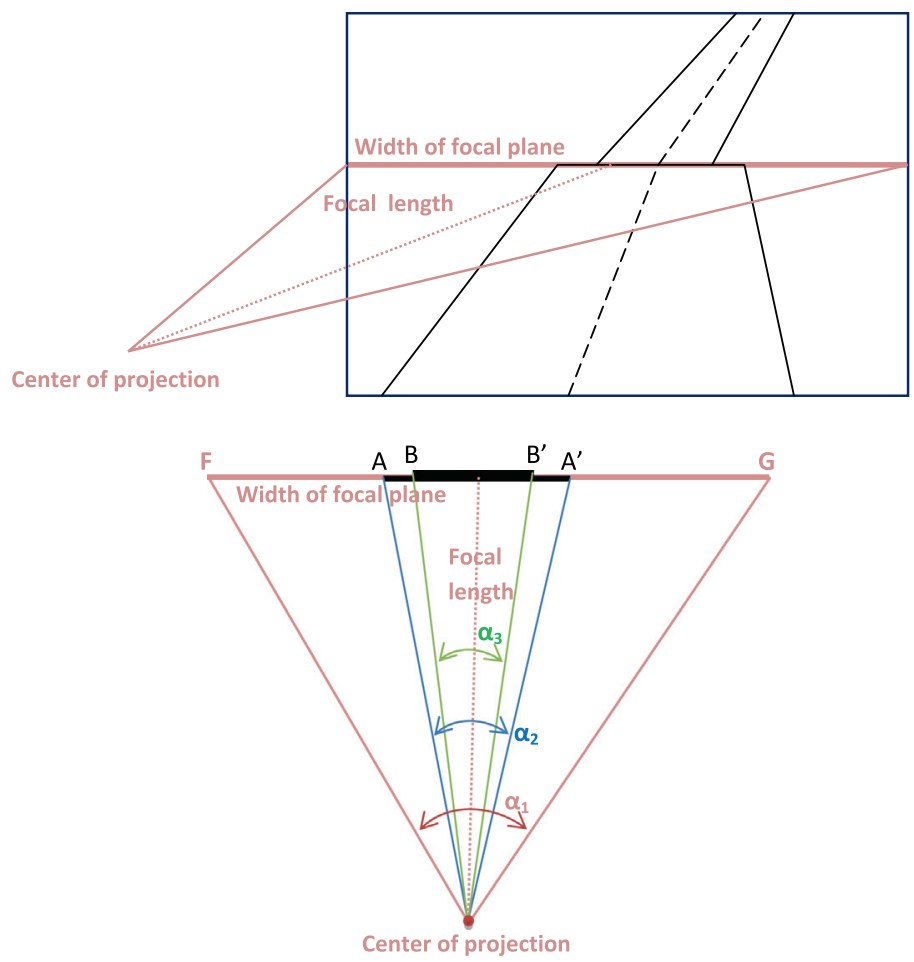

Fig. 4. Geometrical analysis of a diving in a photo.

number by pixel resolution. These coordinates are referred to the left higher vertex of the photo.

Every observed angle $(\alpha)$ is calculated using Eq. (1):

$\alpha=2 \operatorname{arctg} \frac{\text { wphoto } / 2}{f}$

where wphoto is the segment length measured on the photograph and $f$ is focal length. Both variables should be in the same units. Therefore, if focal length is in millimetres then wphoto should be also in millimetres. This is obtained multiplying the number of pixels by pixel resolution (a characteristic of the camera).

Therefore, for width of focal plane, angle $\alpha_{1}$ is (Eq. (2)):

$\alpha_{1}=2 \operatorname{arctg} \frac{\mathrm{FG} / 2}{f}$

For segments $\mathrm{AA}^{\prime}$ and $\mathrm{BB}^{\prime}$, angles $\alpha_{2}$ and $\alpha_{3}$ are determined by Eqs. (3) and (4):

$\alpha_{2}=2 \operatorname{arctg} \frac{\mathrm{AA}^{\prime} / 2}{f}$

$\alpha_{3}=2 \operatorname{arctg} \frac{\mathrm{BB}^{\prime} / 2}{f}$

Eqs. (1)-(4) are valid if segments measured are near to the geometric centre of the photograph (principal point, the point in line with the axis of camera lens).

\subsection{Geometrical analysis of photographed objects}

Angles observed in camera space are the same than in terrain space. Therefore, known angles $\alpha_{2}$ and $\alpha_{3}$, if dis- tances $\mathrm{AA}^{\prime}$ and $\mathrm{BB}^{\prime}$ are known in terrain space (they are known and equal to carriageway width), distance between the observer and every segment could be calculated (Fig. 5). The difference between these distances is the length of the hidden section.

Distance between observer and start of hidden section $\left(D_{2}\right)$ is available sight distance (Eq. (5)). As already mentioned, determination of available sight distance is important for traffic safety because it must be larger than some minimum values established by the corresponding standards.

$D_{2}=\frac{W_{\text {road }} / 2}{\operatorname{tg}\left(\alpha_{2} / 2\right)}$

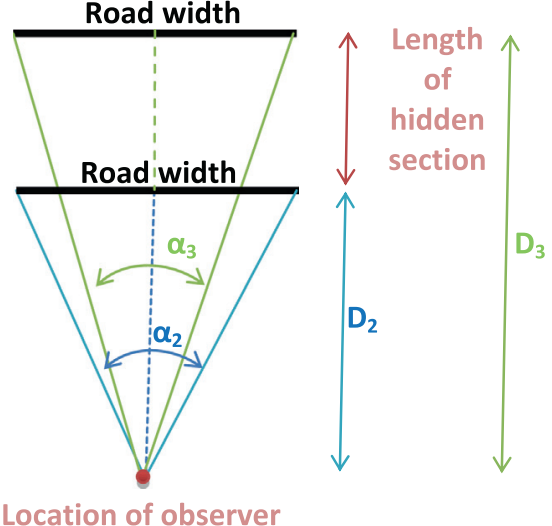

Fig. 5. Geometrical analysis of a diving in terrain space. 
Distance between observer and start of reappeared section $\left(D_{3}\right)$ (Eq. (6)) is also important for traffic safety. In fact, some highway design standards specify minimum values for this distance.

$D_{3}=\frac{W_{\text {road }} / 2}{\operatorname{tg}\left(\alpha_{3} / 2\right)}$

Length of hidden section (CB in Fig. 2) is the difference between these distances (Eq. (7)):

Length of hidden section $=D_{3}-D_{2}$

If the values of the already determined angles (Eqs. (3) and (4)) are substituted in Eqs. (5) and (6), available sight distance $\left(D_{2}\right)$ and distance from the observer to the beginning of reappeared section $\left(D_{3}\right)$ could be expressed as (Eqs. (8) and (9)):

$D_{3}=\frac{W_{\text {road }} / 2}{\mathrm{BB}^{\prime / 2} / f}=\frac{f \cdot W_{\text {road }}}{\mathrm{BB}^{\prime}}$

$D_{2}=\frac{W_{\text {road }} / 2}{\mathrm{AA}^{\prime / 2} / f}=\frac{f \cdot W_{\text {road }}}{\mathrm{AA}^{\prime}}$

\subsection{Summary of the procedure}

The procedure designed for distance measurement includes the following steps:

1. Calibration of the digital camera to reduce measurement errors.

2. Measurement of the highway width in the section where distances will be measured.

3. Taking the photos and registering the camera position with a GNSS receiver. The GNSS could be integrated, or not, in the camera.

4. Measurement of highway width in the photos (in pixels).

5. Calculation of the distances using Eqs. (8) and (9).

6. Calculation of length of hidden section (Eq. (7)).

\section{Error analysis}

The expression used to calculate distances from the observer (Eqs. (8) and (9)) uses three data. So, the distance error could be estimated as (Eq. (10)):

Distance error $=\left(\frac{\Delta f}{f}+\frac{\Delta \text { width }}{\text { width }}+\frac{\Delta \text { pixel }}{\text { pixels }}\right) \cdot$ Distance

The three sources of error could be of very different importance. Focal length is a parameter of the camera that could be known with high precision if the camera is calibrated (as it is in the case study).

Carriageway width is approximately constant along a highway section. Sometimes it increases in curves, but remains constant in tangents. Therefore, as this procedure is valid only for tangents, carriageway width could be considered a known constant whose value could be easily measured when taking the photos.
Regarding the length of segments $\mathrm{AA}^{\prime}$ and $\mathrm{BB}^{\prime}$, as they are measured in a photo, they are measured in pixels. Therefore, their maximum error is one pixel. Obviously, in order to reduce this error the number of pixels in segments $\mathrm{AA}^{\prime}$ or $\mathrm{BB}^{\prime}$ should be as large as possible. So, as higher is the resolution of the camera, more pixels are in these segments and lower measurement errors are got.

\section{Case study}

To demonstrate its performance, the proposed procedure for measuring divings in roads has been applied to a case study. The diving is located in a two-lane rural highway (11.5 station of M-325) between Villamanrique de Tajo and Colmenar de Oreja, Madrid (Spain). In this section, used equipment, procedure application to case study and its verification is described.

\subsection{Materials}

In the aforementioned road section, a series of 25 photographs were taken with a single lens reflex camera (Canon DS500). The camera was located in a way that simulates the point of view of a driver circulating from Villamanrique de Tajo to Colmenar de Oreja. Some photographs were used to apply the procedure and the remaining for verifying it. According to Spanish design standard, height of driver eyes over pavement is $1.1 \mathrm{~m}$. In order to take all the photographs at this height, the camera has been fixed to a tripod. Distance from the centre of the camera lens to the pavement has been fixed to $1.1 \mathrm{~m}$. In Table 2 camera specifications are shown.

In order to determine internal camera parameters with high precision, a camera calibration was made using ImageMaster software from Topcon. In Table 3, camera parameters obtained after the calibration process are

Table 2

Camera specifications.

\begin{tabular}{ll}
\hline Model & Canon EOS 500D \\
Sensor & CMOS 22.3 $\times 14.9 \mathrm{~mm}$ \\
Aspect & $3: 2$ \\
Width & 4752 pixels \\
Height & 3168 pixels \\
Bit depth & 14 \\
\hline
\end{tabular}

Table 3

Camera parameters obtained after calibration.

\begin{tabular}{lll}
\hline Focal length & & $17.947826 \mathrm{~mm}$ \\
Principal point & $X$ & $10.772977 \mathrm{~mm}$ \\
& $Y$ & 7.375022 \\
Distortion function & Distortion model: & 2 \\
& Number of parameters & 4 \\
& Parameter 1 & $5.297334 \times 10^{-4}$ \\
& Parameter 2 & $-1.301606 \times 10^{-6}$ \\
& Parameter 3 & $2.477386 \times 10^{-5}$ \\
Resolution & Parameter 4 & $1.041598 \times 10^{-4}$ \\
& $X$ & $0.0046 \mathrm{~mm} / \mathrm{pixel}$ \\
& $Y$ & $0.0046 \mathrm{~mm} / \mathrm{pixel}$ \\
\hline
\end{tabular}


Table 4

Used GNSS characteristics.

$\begin{array}{lll}\text { Receiver: } & & \text { GNSS GPS + GLoNaSS } \\ \text { Number of channels: } & & 72 \mathrm{GPS}+\text { GLoNaSS L1/L2 } \\ \text { RTK accuracy: } & \mathrm{H}: & 10 \mathrm{~mm}+1.0 \mathrm{ppm} \\ & \mathrm{V}: & 15 \mathrm{~mm}+1.0 \mathrm{ppm} \\ \text { DGPS accuracy: } & & 30 \mathrm{~cm} \mathrm{HECM} \\ \text { L1 static: } & \mathrm{H}: & \text { ECM } 3 \mathrm{~mm}+0.8 \mathrm{ppm} \\ & \mathrm{V}: & \text { ECM } 4 \mathrm{~mm}+1.0 \mathrm{ppm} \\ \text { L1, PP kinematic: } & \mathrm{H}: & \text { ECM } 10 \mathrm{~mm}+1.0 \mathrm{ppm} \\ & \mathrm{V}: & \text { ECM } 15 \mathrm{~mm}+1.0 \mathrm{ppm} \\ \text { WaaS/EGNoS: } & & \text { Yes } \\ \text { CoRS beacon: } & & \text { Yes with BR-1 }\end{array}$

Table 5

Results of diving measurements.

\begin{tabular}{rllll}
\hline Photo & $\begin{array}{l}\text { Persistence } \\
(\mathrm{m})\end{array}$ & $\begin{array}{l}\text { Available } \\
\text { sight } \\
\text { distance } \\
\left(D_{2}\right)(\mathrm{m})\end{array}$ & $\begin{array}{l}\text { Distance from } \\
\text { observer to } \\
\text { reappeared } \\
\text { section }\left(D_{3}\right)(\mathrm{m})\end{array}$ & $\begin{array}{l}\text { Length of } \\
\text { hidden } \\
\text { section } \\
(\mathrm{m})\end{array}$ \\
\hline 4 & 0.0 & 93.4 & 418.0 & 324.7 \\
5 & 4.4 & 95.4 & 399.0 & 303.6 \\
6 & 10.7 & 85.6 & 337.6 & 252.0 \\
7 & 14.9 & 80.9 & 373.6 & 292.7 \\
8 & 19.9 & 70.0 & 351.3 & 281.2 \\
9 & 23.9 & 82.8 & 373.6 & 290.7 \\
10 & 28.5 & 75.7 & 365.8 & 290.1 \\
11 & 33.5 & 69.7 & 325.1 & 255.6 \\
12 & 39.3 & 70.6 & 325.1 & 254.6 \\
13 & 44.6 & 61.0 & 283.2 & 222.2 \\
14 & 50.2 & 63.2 & 262.1 & 198.9 \\
15 & 55.2 & 56.6 & 250.8 & 194.2 \\
16 & 60.6 & 55.2 & 175.6 & 120.4 \\
17 & 65.8 & 50.9 & 147.5 & 78.2 \\
18 & 71.7 & 65.8 & 143.9 & \\
\hline
\end{tabular}

shown. Calibrated focal length was $17.947826 \mathrm{~mm}$. Pixel resolution was $0.0046 \mathrm{~mm} /$ pixel in every direction.

Carriage width $(4.5 \mathrm{~m})$ was measured using a flexible rule with one millimetre accuracy. Camera location (coordinates) was determined using a hand-held double frequency GNSS receiver and high speed processor, Topcon
GRS-1. In Table 4, technical characteristics of the used GNSS are shown. Used reference system was ETRS89, UTM projection zone 30 .

\subsection{Diving parameters calculation}

Photographs where diving appear (from 4 to 18) were selected for procedure application. Using Eqs. (8) and (9), available sight distance $\left(D_{2}\right)$, distance from observer to reappeared section $\left(D_{3}\right)$, and length of hidden section $\left(D_{3}-D_{2}\right)$ were calculated. Also, distance travelled from the first photo (4) to every other photo was determined. Assuming that the first photo (4) corresponds to the beginning of the diving, travelled distance corresponds to phenomenon persistence (road length during which a driver sees a reappeared section). In Table 5 , obtained results are shown. Maximum length of hidden section corresponds to the beginning of the diving and is $324.7 \mathrm{~m}$. Minimum available sight distance is $50.9 \mathrm{~m}$. Maximum distance between observer and reappeared section is $418 \mathrm{~m}$ and corresponds to the beginning of the diving. Fig. 6 shows the length of hidden section evolution when a driver travels on the road. This length diminishes when distance travelled increases.

\subsection{Procedure verification}

In order to verify the proposed procedure, fixed elements existent in the road (traffic signs) were identified before taken the photographs. Also, a pair of ranging poles was installed in both margins of the road. Ranging poles were placed in such a way that a line joining them was orthogonal to road axis.

After the identification of fixed elements and the installation of the ranging poles, distance between each pair of elements were measured. To this aim a flexible rule with $1 \mathrm{~mm}$ accuracy was used, as has been commented in Section 4.1. Fig. 7 shows these elements and the measured distances. The distance between the ranging poles was measured between their internal borders (the nearest to the carriageway). Distance between traffic signs (already

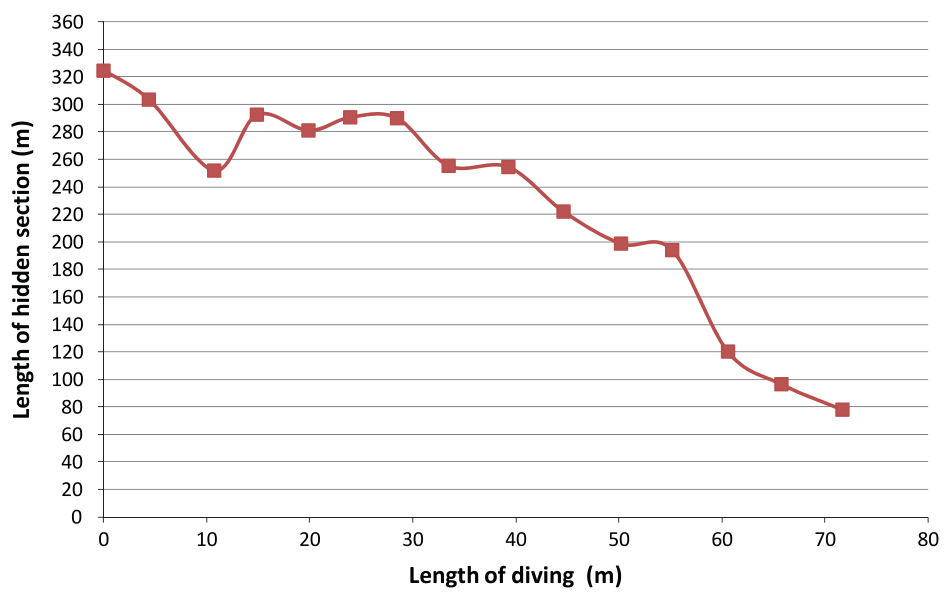

Fig. 6. Length of hidden section vs. length of diving. 


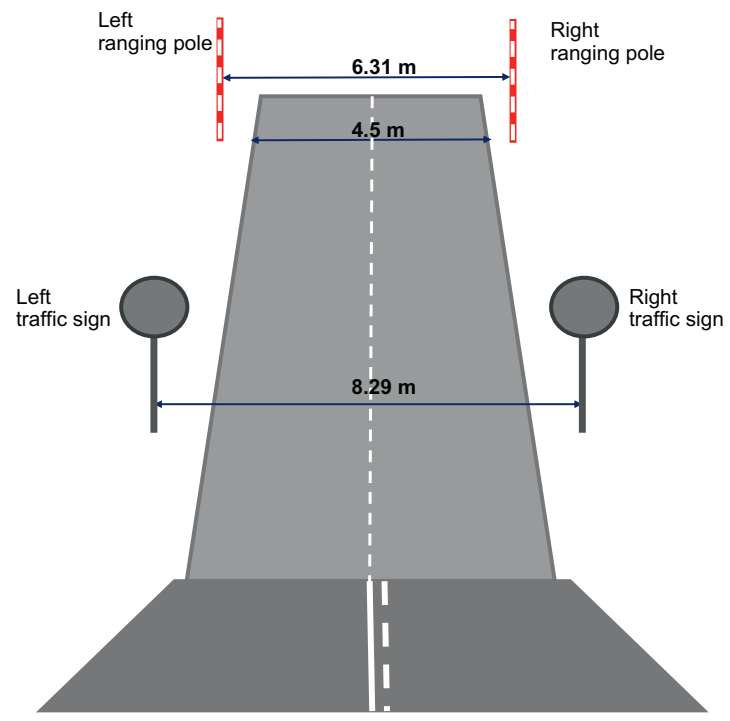

Fig. 7. 3D Scheme of auxiliary elements used for verification.

existent in the road) was measured between the outer borders of their respective posts (the most far away from the carriageway).

Location (coordinates) of the camera and of every fixed element (traffic sign and ranging pole) were determined using the GNSS receiver mentioned in Section 4.1 (Table 3). Fig. 8 shows, on an orthophoto, the location of all the elements used in the data taken in the field (some were used to determine diving parameters and some to verify the procedure).

In order to verify the proposed procedure, photographs from 12 to 25 were used. In these photos, both traffic signs and ranging poles could be seen. As the coordinates of the camera, traffic signs and ranging poles are known, distance
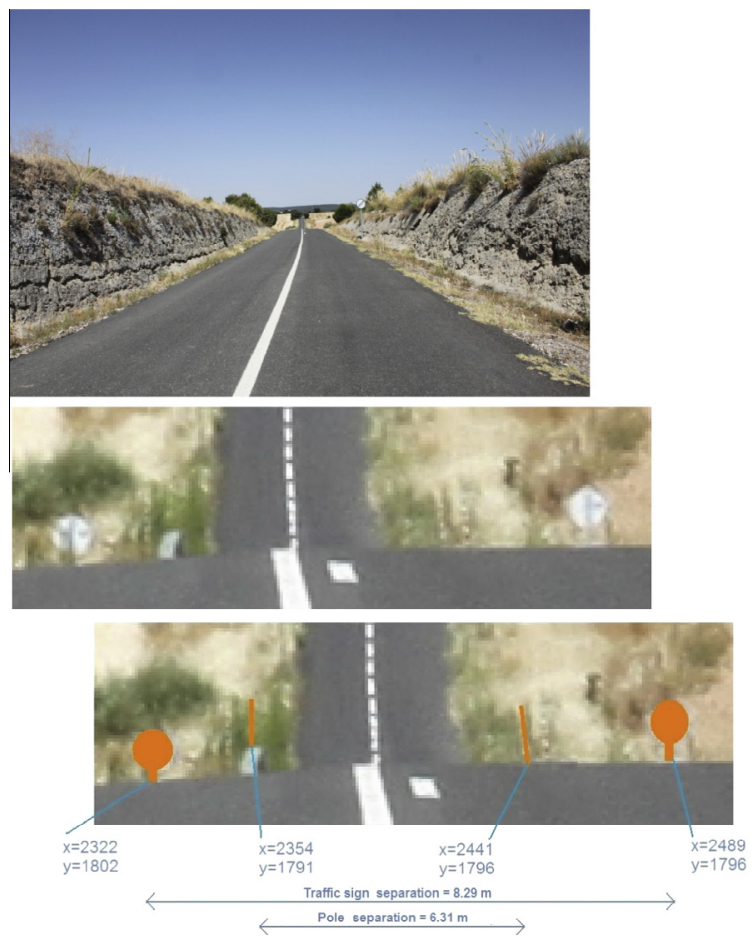

Fig. 9. Zoom in of ranging poles and traffic signs.

between every camera location and the different elements could be determined. These distances were calculated using the proposed procedure from the photographs. In Fig. 9, how the distance between traffic signs were measured on photograph 12 could be appreciated.

In calculations, only the $\mathrm{x}$ coordinates have been used because the geometrical analyses made assume segments parallel to photographs' $x$ axis. In Table 6, width in pixels

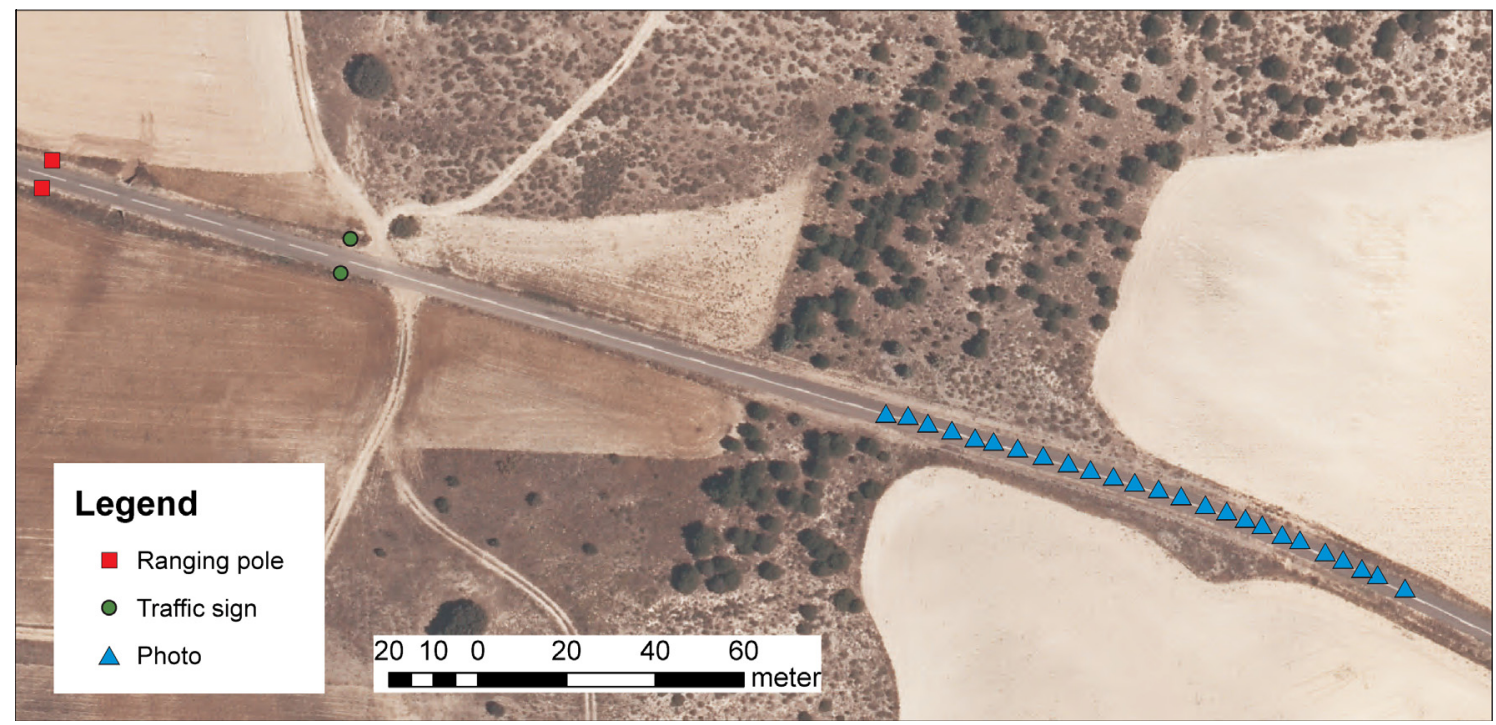

Fig. 8. Diving, traffic signs, ranging poles and camera locations. 
Distances and errors.

\begin{tabular}{|c|c|c|c|c|c|c|c|c|c|c|}
\hline \multirow[t]{2}{*}{ Photo } & \multicolumn{5}{|c|}{ Traffic signs } & \multicolumn{5}{|c|}{ Ranging poles } \\
\hline & $\begin{array}{l}\text { Width } \\
\text { (Pixels) }\end{array}$ & $\begin{array}{l}\text { Distance } \\
\text { from } \\
\text { Photo (m) }\end{array}$ & $\begin{array}{l}\text { Estimated } \\
\text { error }(m)\end{array}$ & $\begin{array}{l}\text { Distance } \\
\text { from } \\
\text { GNSS (m) }\end{array}$ & $\begin{array}{l}\text { Difference } \\
(\mathrm{m})\end{array}$ & $\begin{array}{l}\text { Width } \\
\text { (Pixels) }\end{array}$ & $\begin{array}{l}\text { Distance } \\
\text { from } \\
\text { Photo (m) }\end{array}$ & $\begin{array}{l}\text { Estimated } \\
\text { error }(\mathrm{m})\end{array}$ & $\begin{array}{l}\begin{array}{l}\text { Distance } \\
\text { from }\end{array} \\
\text { GNSS (m) }\end{array}$ & $\begin{array}{l}\text { Difference } \\
(\mathrm{m})\end{array}$ \\
\hline 12 & 165 & 196 & 1.3 & 195.9 & -0.1 & 93 & 265 & 3.1 & 265.4 & 0.4 \\
\hline 13 & 171 & 189 & 1.2 & 190.5 & 1.5 & 95 & 259 & 2.9 & 260.1 & 1.1 \\
\hline 14 & 176 & 184 & 1.2 & 185.0 & 1.0 & 97 & 254 & 2.8 & 254.5 & 0.5 \\
\hline 15 & 180 & 180 & 1.1 & 180.0 & 0.0 & 100 & 246 & 2.7 & 249.5 & 3.5 \\
\hline 16 & 186 & 174 & 1.0 & 174.6 & 0.6 & 101 & 244 & 2.6 & 244.1 & 0.1 \\
\hline 17 & 192 & 168 & 1.0 & 169.4 & 1.4 & 103 & 239 & 2.5 & 238.9 & -0.1 \\
\hline 18 & 198 & 163 & 0.9 & 163.5 & 0.5 & 106 & 232 & 2.4 & 233.0 & 1.0 \\
\hline 19 & 205 & 158 & 0.9 & 157.5 & -0.5 & 109 & 226 & 2.3 & 227.0 & 1.0 \\
\hline 20 & 213 & 152 & 0.8 & 151.9 & -0.1 & 112 & 220 & 2.1 & 221.4 & 1.4 \\
\hline 21 & 221 & 146 & 0.8 & 147.6 & 1.6 & 115 & 214 & 2.0 & 217.2 & 3.2 \\
\hline 22 & 228 & 142 & 0.7 & 142.1 & 0.1 & 116 & 212 & 2.0 & 211.7 & -0.3 \\
\hline 23 & 237 & 136 & 0.7 & 136.5 & 0.5 & 120 & 205 & 1.9 & 206.0 & 1.0 \\
\hline 24 & 247 & 131 & 0.6 & 131.7 & 0.7 & 124 & 199 & 1.8 & 201.3 & 2.3 \\
\hline 25 & 256 & 126 & 0.6 & 126.8 & 0.8 & 126 & 195 & 1.7 & 196.4 & 1.4 \\
\hline Average & & & 0.9 & & & & & 2.3 & & \\
\hline Average square error & & & & & 0.74 & & & & & 1.61 \\
\hline
\end{tabular}

and calculated distances are shown. Distances determined from GNSS receiver data, estimated errors (Eq. (10)) and differences with GNSS determined distances are also shown. Camera parameters used in calculation (focal length and pixel resolution) are, as shown in Table 2, $17.947826 \mathrm{~mm}$ and $0.0046 \mathrm{~mm} /$ pixel, respectively.

As could be seen in Table 6, calculated (using the proposed procedure) and measured (using the GNSS receiver data) values are similar. Mean square error is $0.74 \mathrm{~m}$ for the traffic signs comparison and $1.61 \mathrm{~m}$ for the ranging poles. In both cases, this error is lower than the average estimated error. Thus, error estimation is conservative.

Obtained error when calculating distance to the ranging poles is larger than the error corresponding to traffic signs distance calculation. This is caused by the lower number of pixels between ranging poles. It must be taken into account that the relative error increases when the number of pixels diminishes.

Italian standard [2] provides minimum values for the distance between observer and reappeared section with a minimum increment of $30 \mathrm{~m}$ (Table 1 ). As the proposed procedure determines these distances with a mean square error circa $1 \mathrm{~m}$, it could be considered an error low enough for traffic safety studies.

\section{Conclusions}

A procedure for measuring distances in highways from photographs has been developed. This procedure allows measuring sight distances. The procedure to measure distances consists of six main steps, namely calibration of the digital camera to reduce measurement errors, measurement of the highway width in the section where distances will be measured, taking the photos and registering the camera position with a GNSS receiver, measurement of highway width in the photos (in pixels), calculation of the distances and calculation of length of hidden section.
An estimation of measurements errors has been made. This estimation is usually larger than the true error according to GNSS measured distances. Both, the true error and the estimation are low enough for traffic safety studies.

In the case study, a diving has been considered. Available sight distance, length of hidden section and distance to the reappeared section have been measured. The usefulness of a direct measure of these parameters has been shown.

Future lines of research include using images taken from video cameras and from higher resolution photo cameras.

\section{Acknowledgement}

To the Ministerio de Economía y Competitividad for their support in research project TRA2011-25479. (Convocatoria de 2011 de Proyectos de Investigación Fundamental no Orientada del Plan Nacional de I+D+i 2008-2011)

\section{References}

[1] VSS (1978). Tracé, critères optiques. Swiss norm SN 640 140. Zurich (in French and German).

[2] Ministero delle Infrastrutture e dei Trasporti, Norme funzionali e geometriche per la construzione delle strade. Ministero delle Infrastrutture e dei Trasporti, Roma, 2001 (in Italian).

[3] B.L. Smith, R. Lamm, Coordination of horizontal and vertical alignment with regard to highway esthetics, Transp. Res. Rec. 1445 (1994) 73-85.

[4] T. Janikula, N.W. Garrick, Three-dimensional visualization approach to illustrating esthetic concepts for highway design, Transp. Res. Rec. 1796 (2002) 35-40

[5] American Association of State Highway and Transportation Officials (AASHTO), A policy on geometric design of highways and streets. AASHTO, Washington, D.C, 2004.

[6] Ministerio de Fomento, Norma 3.1-IC Trazado. Ministerio de Fomento, Madrid, 2000 (in Spanish).

[7] A.L. Altamira, J.E. Marcet, A.B. Graffigna, A.M. Gómez, Assessing available sight distance: an indirect tool to evaluate geometric design consistency, in: Proc., 4th Int. Symp. on Highway Geometric Design, TRB, Valencia, Spain, 2010. 
[8] A. Larocca, A. Figueira, J. Quintanilha, F. Kabbach Jr., First steps toward evaluation of efficiency of three-dimensional visualization tools for detecting shortcomings in alignments coordination: a geometric highway project, in: 3rd Int. Conf. on Road Safety and Simulation, TRB, Indianapolis, IN, 2011.

[9] M. Castro, Highway design software as support of a project-based learning course, Comput. Appl. Eng. Educ. 20 (3) (2012) 468-473.

[10] S.M. Easa, Design considerations for highway sight-hidden dips, Transp. Res. Part A: Policy Prac. 28 (1) (1994) 17-29.

[11] M. Zimmermann, Quantitative Methoden zur Beurteilung räumlicher Linienführung von Straßen. Doctoral Dissertation, Karlsruhe Universität, 2001 (in German).
[12] M. Zimmermann, R. Ross, Increased safety resulting from quantitative evaluation of sight distances and visibility conditions of two-lane rural roads, in: Proc., 3rd Int. Symp. on Highway Geometric Design, TRB, Chicago, IL, 2005

[13] W. Kuhn, M.K. Jha, Methodology for checking shortcomings in the three-dimensional alignment, in: Proc., 4th Int. Symp. on Highway Geometric Design, TRB, Valencia, Spain, 2010.

[14] M. Castro, J.A. Anta, L. Iglesias, J.A. Sánchez, GIS-based system for sight distance analysis of highways, J. Comput. Civ. Eng. (2013), http://dx.doi.org/10.1061/(ASCE)CP.1943-5487.0000317. 